\title{
Canine animal as a model in the repercussion of pulmonary stenosis: analysis by two-dimensional echocardiography and doppler mode - case report
}

\begin{abstract}
Pulmonary stenosis is a congenital disease characterized by narrowing of the right ventricular outflow tract. This change results in a resistance to blood flow and, consequently, an increase in the after load, leading to the elevation of systolic pressure of the right ventricle, resulting in concentric hypertrophy. Echocardiographic findings, such as right ventricular diastolic dysfunction, stenosis and pulmonary valve insufficiency, with regurgitant flow observed at color Doppler, were essential for diagnosis. A 5years old small dog, attended at the Hospital Veterinário Universitário HVU/UFPI, was taken as an animal model to report the hemodynamic changes caused by pulmonary insufficiency and stenosis, in a comparative analysis to the same disease when it occurs in humans. Due to the similarities between hemodynamic findings in pulmonary stenosis of dogs and humans, this species proved to be a good animal model to evaluate the repercussion of this congenital heart disease by Doppler echocardiography.
\end{abstract}

Keywords: congenital cardiopathy, diagnostic imaging, cardiology, echocardiography

\author{
Volume 4 Issue 5 - 2017
}

\author{
Renan Paraguassu de Sá Rodrigues,' Gerson \\ Tavares Pessoa, ${ }^{2}$ Laecio da Silva Moura, \\ Francisco das Chagas Araújo Sousa, ${ }^{3}$ Marina \\ Pinto Sanches, ${ }^{2}$ Andrezza Braga Soares \\ da Silva,' Igor Carvalho Santos, ${ }^{4}$ Nathalia \\ Castelo Branco, ${ }^{4}$ Paulo Vitor Silva de \\ Carvalho, ${ }^{5}$ Porfírio Candanedo Guerra, ${ }^{5}$ \\ Jacyara de Jesus Rosa Pereira Alves, ${ }^{6}$ Flávio \\ Ribeiro Alves ${ }^{4}$ \\ 'Animal Science Post-Graduate Program, Federal University of \\ Piauí (UFPI), Brazil \\ ${ }^{2}$ Medical Residence in Veterinary Image Diagnosis, Federal \\ University of Piauí (UFPI), Brazil \\ ${ }^{3}$ Department of Medicine, State University of Piauí, (UESPI), \\ Brazil \\ ${ }^{4}$ Department of Veterinary Morphophysiology, Federal \\ University of Piauí (UFPI), Brazil \\ ${ }^{5}$ Department of Medical Clinic and Surgery, State University of \\ Maranhão, Brazil \\ ${ }^{6}$ Surgery Service of the University Hospital, Federal University
} of Piauí, Brazil

\begin{abstract}
Correspondence: Flávio Ribeiro Alves, Department of Veterinary Morphophysiology, Federal University of Piauí (UFPI), Teresina, Piauí, Brazil, Tel +55 (86) 999587925 ,
\end{abstract} Email flavioribeiro@ufpi.edu.br

Received: October 02, 2017 | Published: December 02, 2017
Abbreviations: $\mathrm{PE}$, pulmonary stenosis; $\mathrm{ACE}$, angiotensin converting enzyme; PGr, pressure gradient; BPM, beats per minute; ECG, electrocardiogram; CHF, congestive heart failure; RV, right ventricle

\section{Introduction}

Pulmonary stenosis (PE) is a heart disease characterized by a narrowing of the right ventricular outflow tract due to the occurrence of a fibrous ring, which may manifest as congenital or rarely acquired. ${ }^{1}$ This change causes resistance to blood flow and an increase in after load, causing elevation of right ventricular systolic pressure, resulting in concentric hypertrophy. Some canine breeds are predisposed to the occurrence of this disease, in general, small breeds such as Schnauzers, Beagles and Cocker Spaniel. ${ }^{2}$

In humans, patients with moderate and severe congenital defects of the pulmonary artery tend to undergo with the increasing repercussion of the disease, ${ }^{3}$ while the discrete defects tend to decrease. ${ }^{4}$ The average longevity of patients with this type of defect is relatively short, due to the appearance of adverse factors in the evolution, responsible for deterioration of ventricular function, mainly represented by hypertrophy, fibrosis and, consequently, heart failure and arrhythmias. ${ }^{5}$

For the diagnosis of PE, imaging techniques such as echocardiography and thoracic radiography play a decisive role. Radiography can demonstrate the right cardiac enlargement pattern, pulmonary trunk distention, and decreased pulmonary vascularization. ${ }^{6}$ The echocardiogram, considered the gold standard for the diagnosis of pulmonary stenosis, may reveal a concentric hypertrophy of the right ventricle, dilation of the pulmonary trunk, enlargement of the right cardiac chambers and an increase in the thickness of the pulmonary valve leaflets. Through the Doppler technique it is possible to identify and determine the exact location of the stenosis. Furthermore, it is used to determine the maximum velocity of blood flow and, therefore, to classify the stenosis according to its severity in mild, moderate and severe. ${ }^{2,7}$

The treatment of this change will depend on the severity of the disease. Patients with pulmonary stenosis classified as mild usually do not require treatment, however, it is indicated a follow-up of the same, with periodic clinical cardiological evaluation and complementary tests to monitor the progression of the disease. ${ }^{8}$ In more severe cases, 
surgical treatment is recommended, in which transcatheter balloon angioplasty or endovascular stent implantation is performed in the stenosed portion, which is the same performed in humans. ${ }^{9,10}$

A 5years old small dog was treated as an animal model at Hospital Veterinário Universitário, from Universidade Federal do Piaui HVU/UFPI, with the objective of reporting the hemodynamic changes caused by pulmonary artery insufficiency and stenosis, in a comparative analysis of the same disease when it occurs in humans.

\section{Case presentation}

It was attended at the Hospital Veterinário Universitário da Universidade Federal do Piauí - HVU/UFPI a female dog, with no defined breed, 5years old, weighing $4.5 \mathrm{~kg}$. During the anamnesis, the owner reported that the animal presented fatigue, respiratory distress, tachypnea, tachycardia and lethargy. During the clinical examination, the animal was slightly dehydrated, pale mucosa, heart rate of $138 \mathrm{bpm}$, ascites and tachypnea. At the auscultation, it was identified grade IV/V systolic murmur, focusing on pulmonary valve. Clinical findings were compatible with heart disease.

The animal was hospitalized and complementary exams such as, thoracic radiography, electrocardiography, echocardiography, abdominal ultrasonography, hemogram and biochemicals were requested. In the hemogram, no abnormalities were found, whereas in the biochemical, there was a decrease in urea and globulin levels and an increase in creatine kinase. Radiographic examination showed an increase in the cardiac silhouette, with loss of definition of the cardiac apex, globose heart, pleural effusion and generalized cardiomegaly (Figure 1A). Abdominal ultrasonography revealed free fluid and thick floating septations with hyper refrigerant echoes. The electrocardiographic examination excluded the presence of arrhythmias and demonstrated findings consistent with atrioventricular overload and myocardial hypoxia (Figure 1B).

The echocardiographic examination revealed:

i. Irregular rhythm,

ii. Heart rate of $120 \mathrm{bpm}$,

iii. Preserved left ventricular systolic function,

iv. Left ventricular diastolic dysfunction grade II,

v. Preserved right ventricular systolic function,

vi. Diastolic dysfunction in the right ventricle,

vii. Stenosis and pulmonary valve insufficiency, with a regurgitant flow of $26 \mathrm{mmHg}$ mild pulmonary hypertension (Figure 1C-1D).

The treatment with intravenous furosemide $(1 \mathrm{mg} / \mathrm{kg})$, benazepril $(0.5 \mathrm{mg} / \mathrm{kg})$ and sildenafil $(1 \mathrm{mg} / \mathrm{kg})$ was started. However, the patient died five days after the consultation due to the aggravation of the case, and the guardian did not authorize the necropsy examination.
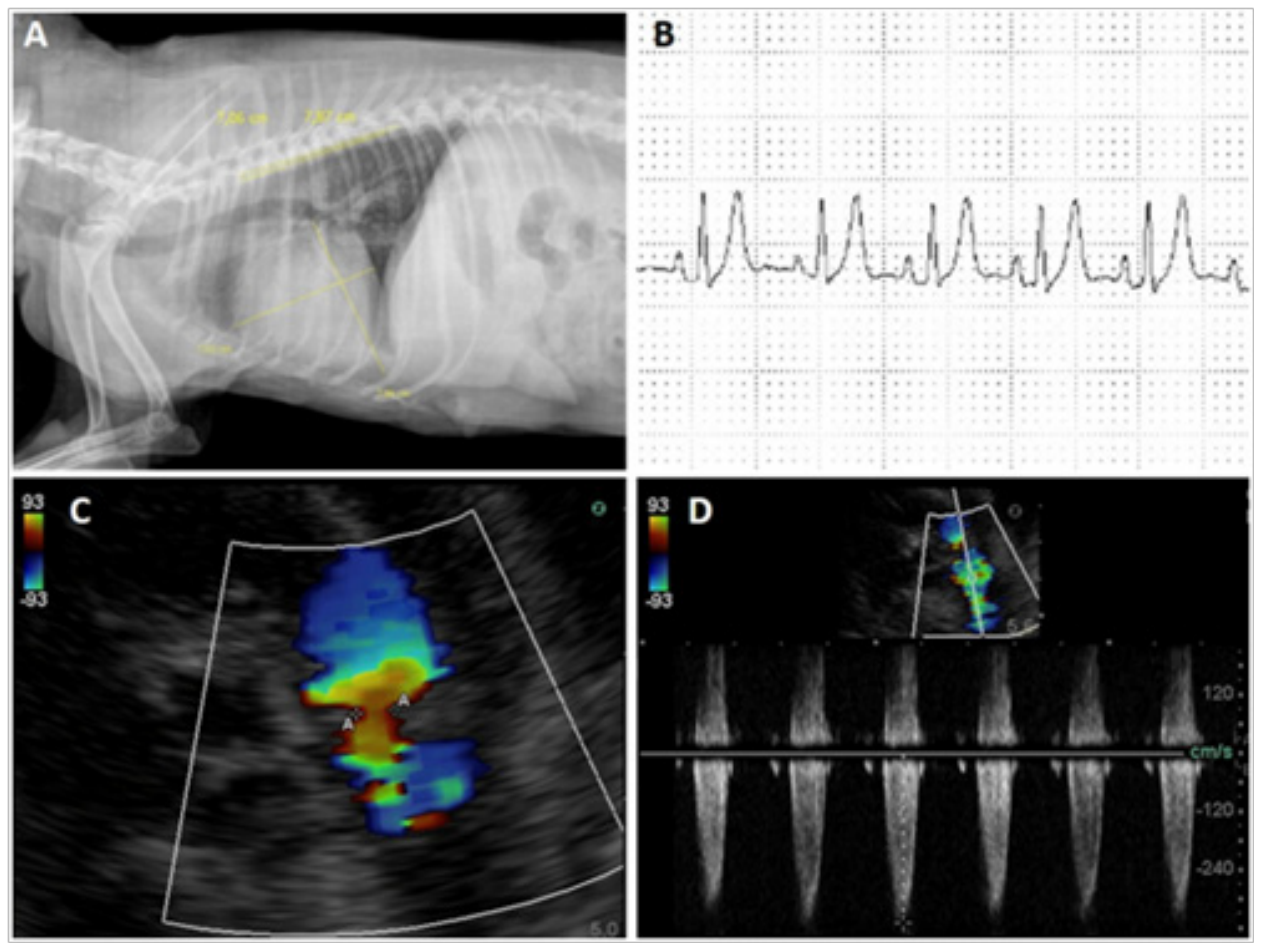

Figure I A, Radiographic examination showed an increase in the cardiac silhouette, with loss of definition of the cardiac apex, globose heart, pleural effusion and generalized cardiomegaly.

$\mathrm{B}$, The electrocardiographic examination excluded the presence of arrhythmias and demonstrated findings consistent with atrioventricular overload and myocardial hypoxia.

C-D, Note the stenosis and pulmonary valve insufficiency, with a regurgitant flow of $26 \mathrm{mmHg}$ mild pulmonary hypertension. 


\section{Discussion}

Pulmonary stenosis is one of the most frequent congenital heart diseases that affect dogs, and may occur alone or in association with other conditions, although the patient in question presented pulmonary stenosis as the only alteration. The signs observed in the clinical examination were consistent with right congestive heart failure (CHF), ${ }^{11}$ and these findings are frequent in small animals, such as the animal in the report. ${ }^{12}$

The stable asymptomatic course that the patient took until the onset of symptoms at a later age is taken as usual, based on the natural history of mild to moderate congenital EP, as well as reported in elderly humans patients. ${ }^{13}$ However, the subsequent progressively symptomatic phase with a severe gradient is relatively rare. This fact may have occurred, among other factors, because of advanced valve insufficiency, an alteration commonly observed in association with congenital PE. ${ }^{14}$

In general, like others congenital heart diseases, pulmonary stenosis is more commonly reported and it has clinical importance in young patients. However, similar to that observed in the present case, some exceptions are described in the human literature, where the disease symptoms are only present in advanced ages. ${ }^{15}$

The clinical signs obtained by the anamneses and physical examination, such as exercise intolerance, respiratory stress, tachypnea, tachycardia and lethargy, were determinate for the suspicion of cardiopathy. The same symptoms have been reported in the literature for humans with PE. ${ }^{16}$ Also, changes reported on Doppler echocardiography, as well as increased right ventricular pressure and hypertrophy, RV diastolic dysfunction, and regurgitant flow pulmonary valve narrowing and failure were similar to findings reported for an adult woman showing the same changes. ${ }^{17}$

The abnormal presence of free abdominal fluid detected on abdominal ultrasonography was a result of important hemodynamic changes, derived from the hydrostatic imbalance of the right cardiac chambers. ${ }^{18}$ The thorax radiograph showed a significant role, allowing the detection of a generalized cardiac enlargement, especially in the atrium and right ventricle, showing an inverted " $D$ " pattern in the dorsoventral projection, in addition to the cardiac silhouette with the sternum, in left lateral projection. In addition, radiographic images allowed to evaluate the evolution of pleural effusion. ${ }^{18,19}$

The electrocardiogram (ECG) was sensitive to the presence of right atrioventricular overload and to the monitoring of the heart rhythm. There was no deviation of the cardiac electric axis, right or left branch block, although these are frequent reports in the human literature patients with stenosis and congenital pulmonary insufficiency. ${ }^{8,20,21}$ In humans, atrial fibrillation, premature ventricular complexes and cardiac electrical axis deviations were reported in patients with PE, however, these patients had other cardiac changes in association. ${ }^{15}$ Although ECG points to indirect signs of changes due to pulmonary disease with repercussions in right heart chambers, these should be investigated by other diagnostic methods, such as spirometry, echocardiography or computed tomography (TC) ${ }^{3,22}$

Echocardiography was very sensitive in the identification of stenosis, as well as in the determination of pulmonary flow velocities and areas of greater turbulence, characterized by color mosaic and spectral waves with absence of systolic window and notches during the wave deceleration phase. The lesion was identified at the valve level, where a blood flow velocity of $201.9 \mathrm{~cm} / \mathrm{s}$ and pressure gradient $(\mathrm{GrP})$ of $26 \mathrm{mmHg}$, mild grade stenosis, was determined. Such alterations are similar to echocardiographic findings in human PD patients, in which pulmonary stenosis, right ventricular hypertrophy, reduced RV systolic function, biatrial enlargement, aortic insufficiency, mitral and tricuspid insufficiency and shunts were reported. However, the severity of these varied changes in each case according to the degree of the change and the presence of other pathologies..$^{15,23}$

Due to these findings, drug therapy ${ }^{24}$ was chosen with the use of an angiotensin converting enzyme (ACE) inhibitor, benazepril, at a dose of $0.5 \mathrm{mg} / \mathrm{kg}$ for the treatment of heart failure, aiming at the relaxation of the right ventricle and, consequently, improvement in the transvalvar gradient. ${ }^{25}$ Pharmacological blockade of ACEactivated hormones or their metabolic pathways prolongs survival in patients with Congestive Heart Failure (CHF). This drug decreases the peripheral vasoconstriction caused by angiotensin II and inhibits sodium and water reabsorption stimulated by the production and release of aldosterone, acting for 24 hours and given once daily. ${ }^{26}$

For the treatment of pulmonary hypertension, we chose to use sildenafil, aiming at cardiovascular stabilization by improving oxygenation and reducing pressure in the pulmonary artery, a similar protocol used in humans. ${ }^{27}$ Sildenafil was studied in animal models of pulmonary hypertension, which showed a selective pulmonary vasodilator with no effect on systemic arterial pressure. ${ }^{28}$ The effects of Sildenafil on pulmonary vasculature are independent of the etiology of pulmonary hypertension, and may vary according to age, except when secondary to congenital heart disease. ${ }^{29}$

However, risk factors may negatively affect the prognosis of patients diagnosed with pulmonary stenosis, such as age at diagnosis (less than one year of age), type B or type 2 stenosis, and concomitant clinical signs of congestive heart failure. Due to the concomitance of the stenosis with signs of congestive heart failure, and the prolonged time from the appearance of the clinical signs until the animal arrives the hospital, the prognosis became unfavorable, favoring the aggravation of the disease, resulting in the death of the animal. ${ }^{30}$

\section{Conclusion}

Although congenital heart diseases are more commonly reported and of greater importance in young animals, they may manifest in patients with more advanced age, causing systemic alterations that require immediate treatment, similar to reported for humans. In this sense, regardless of the cause, it is of the utmost importance for clinicians to be alert to the occurrence of this disease, making possible the early diagnosis through the accomplishment of complementary exams and, consequently, improving the chances of successful treatment. Due to the similarities between hemodynamic findings in pulmonary stenosis of dogs and humans, this species proved to be a good animal model to evaluate the repercussion of this congenital heart disease by Doppler echocardiography.

\section{Acknowledgements}

The authors thank the Diagnosis by Imaging Sector of the 
University Veterinary Hospital, Federal University of Piauí (UFPI) and the Nucleus for Wild Animal Research and Preservation of the UFPI for making the animals available. They also thank the Coordenação de Aperfeiçoamento de Pessoal de Nível Superior (CAPES) for the doctoral grant.

\section{Conflicts of interest}

The authors declare that they have no competing interests.

\section{References}

1. Bacha EA, Kreutzer J. Comprehensive management of branch pulmonary artery stenosis. J Interv Cardiol. 2001;14(3):367-375.

2. Belerenian GC. Estenose Pulmonar. In: Belerenian GC, editor. Afecções Cardiovasculares em Pequenos Animais. Interbook, São Paulo, Brazil; 2003.

3. Wennevold A, Jacobsen JR. Natural history of valvular pulmonary stenosis in children below the age of two years. Longterm follow-up with serial heart catheterizations. Eur J Cardiol. 1978;8(3):371-378.

4. Ardura J, Gonzalez C, Andres J. Does mild pulmonary stenosis progress during chilhood: a study of its natural couse. Clin Cardiol. 2004;27(9):519-522.

5. Campbell M. Natural history of congenital pulmonary stenosis. Brasilian Heart Journal. 1969;31:394.

6. Tylley LP, Goodwin JK. Manual de cardiologia para cães e gatos. São Paulo: Roca; 2002.

7. Muthiah R. Costello syndrome with congenital pulmonary valve stenosis and ventriculomegaly-A case report. Scientific Research. 2016;5(8):250-267.

8. Oyama MA, Sisson D, Thomas WP, et al. Congenital Heard Diseases. In: Ettinger SJ, Feldman EC, editors. Textbook of Veterinary Internal Medicine. Missouri: St. Louis, Elsevier Health Sciences, Saunders; 2005. p. 972-1021.

9. Dean PN, Slack MC. Stent angioplasty to relieve left pulmonary artery obstruction caused by patent ductus arteriosus device occlusion: bipartisan teamwork by two interventional devices. Catheter Cardiovasc Interv. 2013;82(3):480-484.

10. Schwartz MC, Alford TC, Saxonhouse M, et al. Treatment of severe native left pulmonary artery stenosis with coronary stent implantation in a $2.4 \mathrm{~kg}$ neonate. $J$ Invasive Cardiol. 2017;29(9):E105-E106.

11. Macdonald KA. Congenital heart diseases of puppies and kittens Vet Clin North Am Small Anim Pract. 2006;36(3):503-531.

12. Sisson DD. Cardiopatia Congênita. In: Ettinger SJ, Feldman EC, editors. Tratado de Medicina Interna Veterinária: doenças do cão e do gato. Brazil: Elsevier; 2004.

13. Ayad RF, Johnston SB, Grayburn PA, et al. Congenital pulmonic stenosis in a 77year-old woman successfully treated with percutaneous balloon valvuloplasty. Proc (Bayl Univ Med Cent). 2010;23(1):21-23.
14. Covarrubias EA, Sheikh MU, Isner JM, et al. Calcific pulmonic stenosis in adulthood: treatment by valve replacement (porcine xenograft) with postoperative hemodynamic evaluation. Chest. 1979;75(3):399-402.

15. Góes GHB, Rebouças LSL, Vianna MVM, et al. Estenose Pulmonar em Adulta com Síndrome de Noonan: Relato de Caso e Atualização de Literatura. Revista Norte Nordeste de Cardiologia. 2017;7(1):8-11.

16. Cory MJ, Ooi YK, Kelleman MS, et al. Reintervention is associated with improved survival in pediatric patients with pulmonary vein stenosis. JACC Cardiovasc Interv. 2017;10(17):1788-1798.

17. Altin FH, Yildiz O, Karacalilar M, et al. Complete Atrioventricular septal defect and pulmonary stenosis diagnosed in a 49 -yearold woman after 10 uneventful births. Tex Heart Inst J. 2015;42(2):166-168.

18. Kealy JK, McAllister H, Graham JP. O abdome. In: Kealy JK, editor. Radiografia e Ultrassonografia do cão e do gato. Rio de Janeiro: Elsevier; 2012.

19. Ware WA. Cardiopatia Congênita. In: Nelson RW, Couto CG, editors. Medicina Interna de Pequenos Animais. Rio de Janeiro: Elsevier; 2015.

20. Filho JCS, Jorge JC, Franco RP. Alterações eletrocardiográficas de um cão com estenose de valva pulmonar, antes e após terapia a base de maleato de enalapril e atenolol. Acta Veterinária Brasilica. 2011;5(1):92-99.

21. Filippi LH. O eletrocardiograma na medicina veterinária. 1 st ed. São Paulo: Roca; 2011.

22. Liang X, Yang Y, Lin W. Diagnosis of right ventricular outflow tract and intraoperative lesion in patients with right coronary artery sinus rupture by transthoracic echocardiography. Zhong Nan Da Xuе Xue Bao Yi Xue Ban. 2017;42(7):796-801.

23. Kodliwadmath A. Dysplastic pulmonary valve stenosis associated with unilateral absent first metacarpal: A rare association. SAGE Open Med Case Rep. 2017;5:2050313X17726946.

24. Terada M, Watanabe H, Lino K, et al. A estenose pulmonar adequada permitiu a sobrevivência a longo prazo em um paciente com ventrículo único não operado. Journal of American College of Cardiology. 2012;59(13):19-25.

25. Pereira PM, Camacho AA, Morais HA. Tratamento de insuficiência cardíaca com benazepril em cães com cardiomiopatia dilatada e endocardiose. Arq Bras Med Vet Zootec. 2005;57(1):141-148.

26. King JN, Mauron C, Kaiser G. Pharmacokinetics of the active metabolite of benazepril, benazeprilat, and inhibition of plasma angiotensin-converting enzyme activity after single and repeated administrations to dogs. Am J Vet Res. 1995;56(12):1620-1628.

27. Crespo Martinez C, Morales LV, Alonso RH, et al. Primary pulmonary hypertension and its management. Farm Hosp. 2004;28(1):48-55.

28. Weimann J, Ullrich R, Hromi J, et al. Sildenafil is a pulmonary vasodilator in awake lambs with acute pulmonary hypertension. Anesthesiology. 2000;92(6):1702-1712. 
29. Bentlin MR, Saito A, De Luca AKC, et al. Sildenafil for pulmonary hypertension treatment after cardiac surgery. Jornal de Pediatria. 2005;81(2):175-178.
30. Locatelli C, Spalla I, Domenech O, et al. Pulmonic stenosis in dogs survival and risk factors in a retrospective cohort of patients. J Small Anim Pract. 2013;54(9):445-452. 